Yoko Kuroki • Teruaki Iwamoto • Juwon Lee

Miki Yoshiike • Shiari Nozawa - Takayasu Nishida

Ashraf A. Ewis • Hideki Nakamura • Tatsushi Toda

Katsushi Tokunaga • Svetlana E. Kotliarova

Nobuyuki Kondoh • Eitetsu Koh • Mikio Namiki

Toshikatsu Shinka • Yutaka Nakahori

\title{
Spermatogenic ability is different among males in different $Y$ chromosome lineage
}

Received: May 28, 1999 / Accepted: May 29, 1999

\begin{abstract}
It is a controversial question whether sperm concentrations in humans are changing. Several researchers have reported on environmental factors affecting sperm quality, but the influence of genetic factors is still not fully understood. In this study, we examined the relationship between $\mathrm{Y}$ chromosome haplotypes and sperm concentration in fertile males. In addition, we determined the haplotypes of azoospermic patients. The results show that the mean sperm concentration correlates with Y chromosome type. Moreover, the occurrence of azoospermia is related to one particular $\mathrm{Y}$ chromosome lineage. Thus, males with a certain haplotype are at a disadvantage for fathering children. The difference of spermatogenic ability among men is important not only in pursuing male competition as in the past but also as relates to the future of modern human males.
\end{abstract}

Key words Sperm concentration · Azoospermia - Spermatogenic ability · Y chromosome · Haplotype · Male lineage

$\mathrm{Y} \cdot$ Kuroki $\cdot$ J. Lee $\cdot$ A.A. Ewis $\cdot$ H. Nakamura $\cdot$ T. Shinka $\cdot$ Y. Nakahori $(\square)$

Department of Public Health, School of Medicine, University of Tokushima 3-18-15 Kuramoto-cho, Tokushima 770-8503, Japan Tel. +81-88-633-7075; Fax +81-88-633-7453

e-mail: nakahori@basic.med.tokushima-u.ac.jp

T. Iwamoto $\cdot$ M. Yoshiike $\cdot \mathrm{S}$. Nozawa $\cdot$ T. Nishida

Department of Urology, School of Medicine, St. Marianna

University, Kawasaki, Japan

T. Toda

Laboratory of Genome Medicine, Human Genome Center, Institute of Medical Science, University of Tokyo, Tokyo, Japan

Y. Kuroki $\cdot$ K. Tokunaga $\cdot$ S.E. Kotliarova

Department of Human Genetics, Graduate School of Medicine,

University of Tokyo, Tokyo, Japan

N. Kondoh

Department of Urology, Osaka central hospital, Osaka, Japan

E. Koh $\cdot$ M. Namiki

Department of Urology, School of Medicine, Kanazawa University,

Kanazawa, Japan

\section{Introduction}

Recently, several researchers have studied sperm concentrations in humans, and some describe it as decreasing (Carlsen et al. 1992; Auger et al. 1995; Irvine et al. 1996), while others describe it as not changing (Olsen et al. 1995; Fisch et al. 1996; Paulsen et al. 1996). In 1992, Carlsen et al. reviewed sperm concentrations in papers published during the past 50 years. She concluded that semen quality including sperm concentration is decreasing and consequently the number of subfertile men is increasing (Carlsen et al. 1992). Also, Mouzon and Thonneau in 1996 reported that sperm count and semen quality has declined among men born in France since 1950 (Mouzon and Thonneau 1996).

Many factors influence sperm quality. Sperm quality is affected by smoking (Chia et al. 1994), alcohol intake (Pajarinen et al. 1996), vibrations (Penkov et al. 1996), physiological stress (Fenster et al. 1997), and exposure to environmental chemicals. Environmental chemicals, especially endocrine-disrupting compounds, have potential hazards that deteriorate male reproductive ability. To date, two genes have been reported as genetic factors for sperm quality, the HLA-DPB1 gene, which correlates with sperm concentration (Chan et al. 1994), and a polymorphism of cytochrome P450-1A1, the frequency of which is elevated in infertile men (Fritsche et al. 1998).

Several researchers have described that the crucial gene(s) for spermatogenesis exist on the $\mathrm{Y}$ chromosome (Tiepolo and Zuffardi 1976; Nakahori et al. 1996), and two candidate genes for azoospermia, RBM (Ma et al. 1993) and DAZ (Reijo et al. 1995), have been identified.

However, the genetic contribution in the process of spermatogenesis, particularly the role of the $\mathrm{Y}$ chromosome in determination of semen quality, is still obscure. We have hypothesized that $\mathrm{Y}$ chromosomes from different male lineages have different structures and different constituent genes involved in spermatogenesis. In our previous study, we classified Japanese males into four Y haplotypes according to three polymorphisms, SRY, YAP, and 47z/Stu I (Shinka et al. 1999). We also demonstrated that the 
haplotypes I and II are common all over the world whereas the haplotypes III and IV are specific to East Asia (Shinka et al. 1999). Using this method, we examined the relationship between Y chromosome haplotypes and sperm concentration of fertile men. We also examined the prevalence of azoospermia in different haplotypes.

\section{Methods}

\section{Subjects}

Semen and blood samples were obtained from healthy fertile Japanese men who had fathered at least one child. These samples were collected at three hospitals in Kanagawa prefecture, which is near Tokyo, Japan. The other samples derived from azoospermic men were collected in Kanagawa and Osaka prefectures in Japan. We also obtained samples from normal fertile men in these districts as a control for reproductive ability. Informed consent was obtained from all participants. Semen samples were obtained by masturbation after sexual abstinence for at least $48 \mathrm{~h}$. All samples were examined within $1 \mathrm{~h}$ of ejaculation. For all the collected ejaculates, sperm concentrations were assessed using a hemocytometer. Only spermatozoa with tails were counted, using a total microscope magnification of $400 \times$. At least two chambers of the hemocytometer were counted, and their average was calculated. Genomic DNA from the blood was isolated by a commercially obtained DNA extraction kit (QIAamp, QIAGEN GmbH, Germany).

\section{Y haplotype analysis}

The haplotype analysis of the Y chromosome was performed by the method reported previously (Shinka et al. 1999). In brief, this method determines the DNA types by PCR-SSCP, PCR-RFLP, and PCR for three polymorphic loci, SRY, DXYS5Y (47z/Stu I), and DYS287 (YAP). By the combination of these three polymorphisms, Y chromosomes were classified into four Y haplotypes: I, II, III, and IV.

\section{Statistical methods}

Statistical analyses were done on a computer using Microsoft Excel and HALBAU (High-quality Analysis Libraries for Business and Academic Users) software (Yanai et al. 1991). For sperm concentrations, most of the analyses were processed using the value transformed by a logarithm (Berman et al. 1996). The mean sperm concentrations were evaluated and compared by one-way and two-way analysis of variance, and their differences were compared by Bonferroni's multiple comparison. The prevalence of azoospermia in haplotypes was examined by the chi-square test.

\section{Results}

We examined the haplotypes and sperm concentration of 198 normal fertile men who participated in this study as volunteers. Haplotype analysis revealed that they consisted of 94 males of haplotype I, 44 of haplotype II, 19 of haplotype III, and 41 of haplotype IV. Their mean age was $32.2 \pm$ 5.1 years old. Their frequency distribution by haplotypes and mean sperm concentration (log-transformed) are presented in Table 1, and their distribution is shown as a histogram in Fig. 1. Sperm concentration is indicated as log-transformed value for clarifying the difference in distribution (Berman et al. 1996). In the range under $1 \times 10^{7}$, there are 13 men with haplotypes I and II, but only 1 man with haplotype III and no one with haplotype IV. Haplotypes I and II have normal distributions, while the distributions of haplotypes III and IV are biased toward higher sperm concentrations.

We classified these 198 subjects into three groups for statistical analysis: those with haplotype I as group A, haplotype II as group B, and haplotypes III and IV as group C. We gathered haplotypes III and IV into one group because of our previous finding that both haplotypes are derived from a common ancestor (Shinka et al. 1999). The mean sperm concentration of each group is shown in Table 2 . In total, the mean sperm concentration of group B was $83.42 \pm 71.23$, which was significantly lower than that of group $\mathrm{C}(P=0.008)$. The differences between groups $\mathrm{A}$ and B $(P=0.054)$ or between groups A and C $(P=0.285)$ were not statistically significant with these sample numbers. To test the effect of age, we classified the males into two categories using 30 years of age as the cutoff point. Below

Table 1. The Y haplotype frequency and mean sperm concentration in normal fertile men

\begin{tabular}{|c|c|c|c|}
\hline & \multicolumn{2}{|l|}{ Samples } & \multirow{2}{*}{$\begin{array}{l}\text { Sperm concentration } \\
{\left[\text { mean } \pm \mathrm{SD}\left(\times 10^{6} / \mathrm{ml}\right)\right]} \\
(\text { log-transformed })\end{array}$} \\
\hline & Number & $(\%)$ & \\
\hline Haplotype I & 94 & $(47.5)$ & $103.59 \pm 84.43(1.85 \pm 0.42)$ \\
\hline Haplotype II & 44 & $(22.2)$ & $83.42 \pm 71.23(1.70 \pm 0.54)$ \\
\hline Haplotype III & 19 & $(9.6)$ & $119.87 \pm 68.92(1.96 \pm 0.37)$ \\
\hline Haplotype IV & 41 & (20.7) & $109.05 \pm 82.71(1.91 \pm 0.34)$ \\
\hline Total & 198 & $(100.0)$ & $101.80 \pm 80.64(1.84 \pm 0.44)$ \\
\hline
\end{tabular}

Table 2. Mean sperm concentration of fertile males in different age groups

\begin{tabular}{rlll}
\hline & Below 30 years & Above 30 years & Total \\
\hline Group A & $\begin{array}{l}105.60 \pm 86.38 \\
(n=40)\end{array}$ & $\begin{array}{l}102.10 \pm 82.92 \\
(n=54)\end{array}$ & $\begin{array}{l}103.59 \pm 84.43 \\
(n=94)\end{array}$ \\
Group B & $102.29 \pm 70.01$ & $\begin{array}{l}71.53 \pm 69.40^{*} \\
(n=27)\end{array}$ & $\begin{array}{l}83.42 \pm 71.23^{* *} \\
(n=44)\end{array}$ \\
Group C & $\begin{array}{c}(n=17) \\
(n=22)\end{array}$ & $\begin{array}{l}(n=26.22 \pm 86.22 \\
(n=38)\end{array}$ & $\begin{array}{l}112.48 \pm 78.77 \\
(n=60)\end{array}$ \\
Total & $100.19 \pm 75.99$ & $102.87 \pm 83.57$ & $\begin{array}{l}101.80 \pm 80.64 \\
(n=198)\end{array}$ \\
& $(n=79)$ & $(n=119)$ & $(n=49$
\end{tabular}

*, $P=0.001,{ }^{* *}, P=0.008$, between groups $\mathrm{B}$ and $\mathrm{C}$ 
Fig. 1. Histogram of sperm concentration transformed by logarithms. Sperm concentration is indicated as log-transformed value based on $10^{7}$; e.g., 1 is equal to $1 \times 10^{7} / \mathrm{ml}, 2$ is equal to $1 \times 10^{8} / \mathrm{ml}$

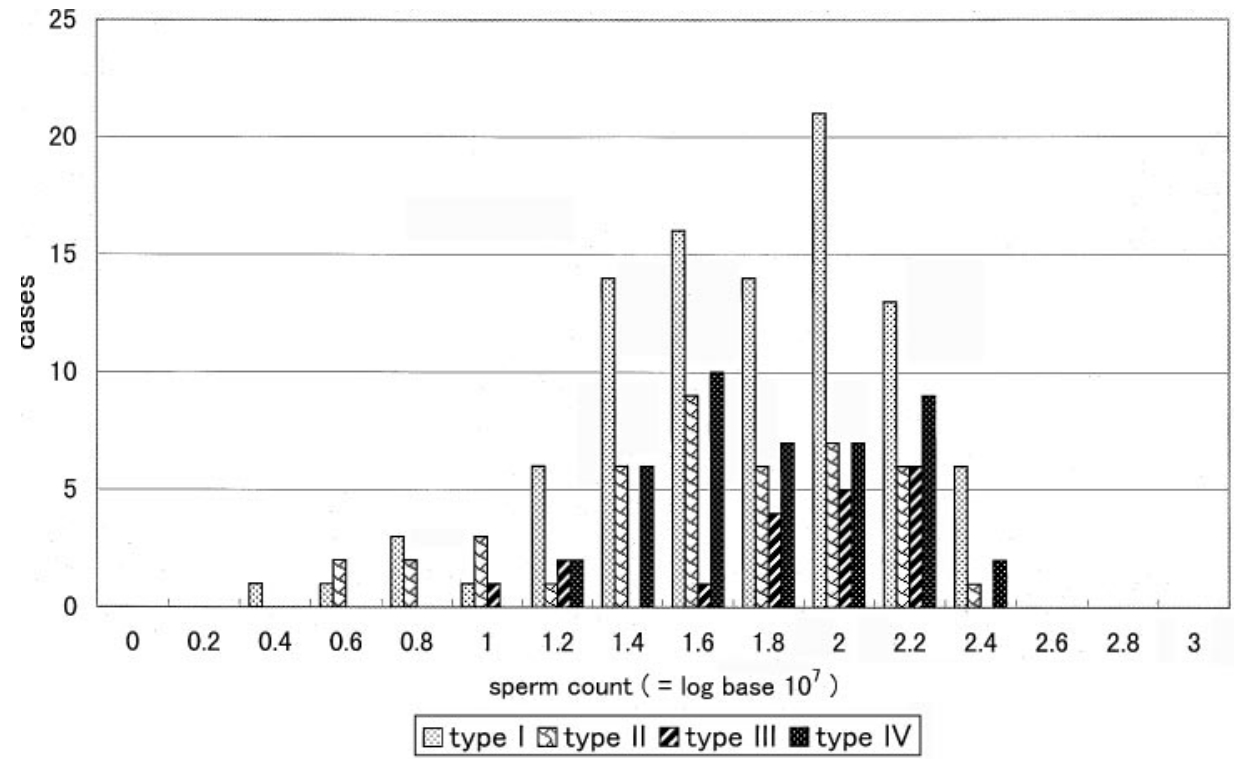

Table 3. The occurrence of azoospermia in different groups

\begin{tabular}{|c|c|c|c|c|c|}
\hline & \multicolumn{2}{|c|}{$\begin{array}{l}\text { Number of samples from } \\
\text { Kanagawa }\end{array}$} & \multicolumn{2}{|c|}{$\begin{array}{l}\text { Number of samples from } \\
\text { Osaka }\end{array}$} & \multirow[b]{2}{*}{ Odds ratio } \\
\hline & Azoospermia & Control & Azoospermia & Control & \\
\hline Group A & $19(45 \%)$ & $50(43 \%)$ & $28(44 \%)$ & $17(44 \%)$ & 1.52 \\
\hline Group B & $15(36 \%)$ & $30(25 \%)$ & $20(31 \%)$ & $7(18 \%)$ & $2.05 *$ \\
\hline Group C & $8(19 \%)$ & $37(32 \%)$ & $16(25 \%)$ & $15(38 \%)$ & 1.00 \\
\hline Total & $42(100 \%)$ & $117(100 \%)$ & $64(100 \%)$ & $39(100 \%)$ & \\
\hline
\end{tabular}

*, $P=0.034$ between groups $\mathrm{B}$ and $\mathrm{C}$

the age of 30, no significant differences were detected among the haplotypes. Surprisingly, above the age of 30, the mean sperm concentration in group B $(71.53 \pm 69.40)$ was much lower than that of the others $(P=0.001)$. In contrast, sperm concentration of group $\mathrm{C}$ increased after 30 years old.

In our previous study, we examined DNA samples from men with azoospermia of unknown causes and showed that almost one-tenth of the patients had a deletion in interval 6 of the Y chromosome long arm (Kobayashi et al. 1994). Therefore, we categorized azoospermic patients in this study as with or without this deletion. The haplotypes were determined for 106 azoospermic men with no Y chromosome deletions and 156 fertile men as controls from two different districts, Kanagawa and Osaka (Table 3). Statistical analysis by the chi-square test showed a significant difference between groups $\mathrm{B}$ and $\mathrm{C}(P=0.03)$. The odds ratio of group B against group C was 2.05 with a confidence interval of $0.996-4.235$, which means that group B has twice the risk of becoming azoospermic as group C. Haplotype analysis of 11 azoospermic patients with a deletion showed 6 were haplotype I, 3 were haplotype II, 2 were haplotype IV, and none were haplotype III.

\section{Discussion}

This study showed that sperm concentration may be affected by genes on the Y chromosome. We found two points of interest. First, in the analysis of the normal fertile men, the mean sperm concentration of those having Y chromosome haplotype II was significantly lower than those who have Y chromosome haplotypes III and IV $(P=0.008)$. Second, the frequency of azoospermia was higher in men having haplotype II.

Recently, it has been reported that a sperm concentration of $40 \times 10^{6} \mathrm{sperm} / \mathrm{ml}$ or lower is associated with a low likelihood of pregnancy, and this level has been recommended to be considered as the threshold between subfertile and fertile men (Bonde et al. 1998). In the present study, the proportion of men whose sperm concentration was less than $40 \times 10^{6} \mathrm{sperm} / \mathrm{ml}$ was $34 \%$ of the males with haplotype II, while it was $27 \%$ in haplotype I and $17 \%$ in haplotypes III and IV. Thus, men with haplotype II are more liable to become subfertile.

Spermatogenesis involves several complex processes, and there are many factors that may affect each step during 
sperm maturation. Other than environmental factors, however, the role of genetic factors must not be underestimated. Here, we focused on the differences of sperm concentrations among the $\mathrm{Y}$ chromosome types according to the hypothesis that $\mathrm{Y}$ chromosomes from different lineages have different constituent genes involved in spermatogenesis.

As expected, we found $\mathrm{Y}$ chromosome lineage correlates with sperm count and the incidence of azoospermia. These results can be explained in two ways. Sperm productivity is affected by $\mathrm{Y}$ chromosome structure, or different $\mathrm{Y}$ chromosomes differ in their ability to resist environmental factors that deteriorate sperm quality. In azoospermic patients, two candidate genes for azoospermia, RBM (Ma et al. 1993) and DAZ (Reijo et al. 1995), have been shown to be located on the Y chromosome. They exist as multiple gene families, and each copy is scattered over the Y chromosome, mainly on the distal region of the long arm (Yen 1998). The maps of the yeast artificial chromosomes (YACs) in this region showed a discrepancy between the YACs of different origin (Yen 1998), which indicated that the constitution of the genes was different among males. Structural differences in the Y chromosome may play an important role in the determination of sperm concentration.

This is the first report that correlates sperm concentration and the type of $\mathrm{Y}$ chromosome. If the different male lineages have different reproductive potential, the Y chromosome type is one of the most important factors in pursuing human male dispersion and in foreseeing the future of present males. Further investigation on the $\mathrm{Y}$ chromosome structure ( $\mathrm{Y}$ chromosome genome project) is needed to evaluate this hypothesis.

Acknowledgments We thank Yasuo Nakagome for valuable discussion, Kazuhiro Kobayashi and Keiko Tomita for technical advice, and Ayuchi Tsuboi-Tamura and Takushi Naroda for critical reading of the manuscript. This work was supported by a fellowship from JSPS, the grants from the Ministry of Health and Welfare, and from the Ministry of Education, Science and Culture, Japan.

\section{References}

Auger J, Kunstmann JM, Czyglik F, Jouannet P (1995) Decline in semen quality among fertile men in Paris during the past 20 years. N Engl J Med 332: 281-285

Berman N, Wang C, Paulsen CA (1996) Methodological issues in the analysis of human sperm concentration data. J Androl 17:68-73

Bonde JPE, Ernst E, Jensen TK, Hjollund NHI, Kolstad H, Henriksen TB, Schelike T, Giwercman A, Olsen J, Skakkebaek NE (1998) Relation between semen quality and fertility: a population-based study of 430 first-pregnancy planners. Lancet 352:1172-1177

Carlsen E, Giwercman A, Keiding N, Skakkebaek NE (1992) Evidence for decreasing quality of semen during past 50 years. Br Med J 305:609-613

Chan PJ, Su BC, Kalugdan TH, Tredway DR (1994) The relationship between human sperm fertilizing capacity and histocompatibility linked antigen (HLA) alleles gene sequences. Hum Reprod (Oxf) 9:279-283

Chia SE, Xu B, Ong CN, Tsakok FM, Lee ST (1994) Effect of cadmium and cigarette smoking on human semen quality. Int J Fertil Menopausal Stud 39:292-298

Fenster L, Katz DF, Wyrobek AJ, Pieper C, Rempel DM, Oman D, Swan SH (1997) Effects of psychological stress on human semen quality. J Androl 18:194-202

Fisch H, Goluboff ET, Olson JH, Feldshuh J, Broder SJ, Barad DH (1996) Semen analyses in 1,283 men from the United States over a 25-year period: no decline in quality. Fertil Steril 65:1009-1014

Fritsche E, Schuppe HC, Dohr O, Ruzicka T, Gleichmann E, Abel J (1998) Increased frequencies of cytochrome P4501A1 polymorphisms in infertile men. Andrologia 30:125-128

Irvine S, Cawood E, Richardson D, MacDonald E, Aitken J (1996) Evidence of deteriorating semen quality in the United Kingdom: birth cohort study in 577 men in Scotland over 11 years. Br Med J 312:467-471

Kobayashi K, Mizuno K, Hida A, Komaki R, Tomita K, Matsushita I, Namiki M, Iwamoto T, Tamura S, Minowada S, Nakahori Y, Nakagome Y (1994) PCR analysis of the Y chromosome long arm in azoospermic patients: evidence for a second locus required for spermatogenesis. Hum Mol Genet 3:1965-1967

Ma K, Inglis JD, Sharkey A, Bickmore WA, Hill RE, Prosser EJ, Speed RM, Thomson EJ, Jobling M, Taylor K, Wolfe J, Cooke HJ, Hargreave TB, Chandley A (1993) A Y chromosome gene family with RNA-binding protein homology: candidates for the azoospermia factor AZF controlling human spermatogenesis. Cell 75:12871295

Mouzon JD, Thonneau P (1996) Semen quality has declined among men born in France since 1950. Br Med J 313:43

Nakahori Y, Kuroki Y, Komaki R, Kondoh N, Namiki M, Iwamoto T, Toda T, Kobayashi K (1996) The Y chromosome region essential for spermatogenesis. Horm Res (Basel) 46:20-23

Olsen GW, Bodner KM, Ramlow JM, Ross CE, Lipshultz LI (1995) Have sperm counts been reduced 50 percent in 50 years? A statistical model revisited. Fertil Steril 63:887-893

Pajarinen J, Karhunen PJ, Savolainen V, Lalu K, Penttila A, Laippala P (1996) Moderate alcohol consumption and disorders of human spermatogenesis. Alcohol Clin Exp Res 20:332-337

Paulsen CA, Berman NG, Wang C (1996) Data from men in greater Seattle area reveals no downward trend in semen quality: further evidence that deterioration of semen quality is not geographically uniform. Fertil Steril 65:1015-1020

Penkov A, Stanislavov R, Tzvetkov D (1996) Male reproductive function in workers exposed to vibration. Cent Eur J Public Health 4:185-188

Reijo R, Lee TY, Salo P, Alagappan R, Brown LG, Rosenberg M, Rozen S, Jaffe T, Straus D, Hovatta O, de la Chapell A, Silber S, Page DC (1995) Diverse spermatogenic defects in humans caused by $\mathrm{Y}$ chromosome deletions encompassing a novel RNA-binding protein gene. Nat Genet 10:383-393

Shinka T, Tomita K, Toda T, Kotliarova SE, Lee Juwon, Kuroki Y, Jin DK, Tokunaga K, Nakamura H, Nakahori Y (1999) Genetic variations on the $\mathrm{Y}$ chromosome in the Japanese population and implications for modern human $\mathrm{Y}$ chromosome lineage. J Hum Genet 44:240-245

Tiepolo L, Zuffardi O (1976) Localization of factors controlling spermatogenesis in the nonfluorescent portion of the human Y chromosome long arm. Hum Genet 34:119-124

Yanai H, Takagi T, Ichikawa M, Hattori Y, Satoh T, Marui E (1991) The handbook of multivariate analysis (in Japanese). Gendaisuugaku-sha, Kyoto

Yen PH (1998) A long-range restriction map of deletion interval 6 of the human Y chromosome: a region frequently deleted in azoospermic males. Genomics 54:5-12 